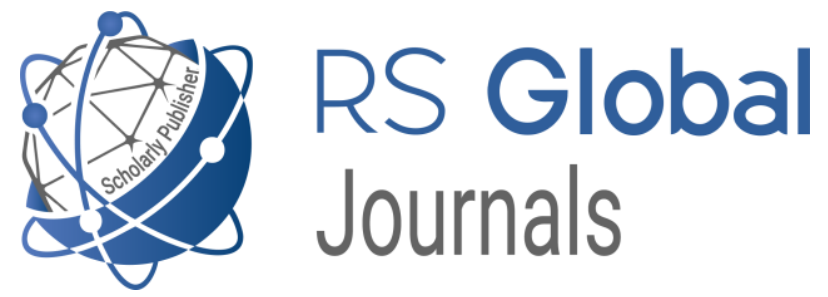

JOURNAL Science Review

p-ISSN 2544-9346

e-ISSN 2544-9443

PUBLISHER RS Global Sp. z O.O., Poland

$\begin{array}{ll}\text { ARTICLE TITLE } & \text { APPLICATION OF TOPSIS METHOD WITH } \\ \text { TRAPEZOIDAL FUZZY NUMBERS }\end{array}$

AUTHOR(S) Salimov Vagif Hasan Oglu

Vagif Salimov. (2021) Application of TOPSIS Method with

ARTICLE INFO Trapezoidal Fuzzy Numbers. Science Review. 1(36).

doi: 10.31435/rsglobal_sr/30012021/7377

DOI https://doi.org/10.31435/rsglobal_sr/30012021/7377

RECEIVED 25 November 2020

ACCEPTED 17 January 2021

PUBLISHED 22 January 2021

LICENSE This work is licensed under a Creative Commons Attribution

4.0 International License.

(C) The author(s) 2021. This publication is an open access article. 


\title{
APPLICATION OF TOPSIS METHOD WITH TRAPEZOIDAL FUZZY NUMBERS
}

\author{
Salimov Vagif Hasan Oglu, Ph.D., assoc. prof. of "Computer engineering" department, Azerbaijan \\ state oil and industry university, Baku, Azerbaijan Republic, \\ ORCID ID: https://orcid.org/0000-0002-0590-5437
}

DOI: https://doi.org/10.31435/rsglobal_sr/30012021/7377

\section{ARTICLE INFO}

Received 25 November 2020

Accepted 17 January 2021

Published 22 January 2021

\section{KEYWORDS}

multi-criteria decision making, alternative, criterion, fuzzy,

TOPSIS method, ideal

solution, distance to ideal

solution, equipment.

\begin{abstract}
The article is devoted to the problem of multi-criteria decision making. As application problem is used the equipment selection problem. The analysis of existing methods for solving this problem is given. As a method for solving this problem fuzzy TOPSIS (The Technique for Order of Preference by Similarity to Ideal Solution) is proposed. This method is based on ideal solution approach. The issues of practical implementation of this method are discussed in details. The results of the solution test problem at all stages are presented.
\end{abstract}

Citation: Vagif Salimov. (2021) Application of TOPSIS Method with Trapezoidal Fuzzy Numbers. Science Review. 1(36). doi: 10.31435/rsglobal_sr/30012021/7377

Copyright: (C) 2021 Vagif Salimov. This is an open-access article distributed under the terms of the Creative Commons Attribution License (CC BY). The use, distribution or reproduction in other forums is permitted, provided the original author(s) or licensor are credited and that the original publication in this journal is cited, in accordance with accepted academic practice. No use, distribution or reproduction is permitted which does not comply with these terms.

Introduction. Multi Criteria Decision making - (MCDM) is one of the actual problem in the theory of decision making [1-2]. From a mathematical point of view, it belongs to the class of vector optimization problems. The criteria can be divided into two groups: the criteria for which the maximum value is optimal and the criteria for which the minimum value is optimal. MCDM problems can be solved with an accuracy of many non- dominated alternatives or many trade-offs. Obtaining a single solution can only be implemented on the basis of some compromise scheme that reflects the preferences of the decision maker (DM). Methods for solving this problem can be divided into two large groups: methods using the aggregation of all alternatives according to all criteria and the solution of the resulting single-criterion problem, the second group is associated with the procedure of pairwise comparisons and stepwise aggregation. The first group includes methods: weighted average sum, weighted average product and their various modifications [3-4], the second group includes -Analytical Hierarchy Process (AHP), Elimination and Choice Translating Reality (ELECTRE), The Technique for Order of Preference by Similarity to Ideal Solution (TOPSIS), Preference Ranking Organization Method (PROMETHEE) [5-13]. The work [3] provides information on the popularity of various methods of multi-criteria decision-making. This paper discusses the TOPSIS method.

The TOPSIS method was developed by Hwang and Yoon in 1981. This method was very popular for solving multi-criteria problem under certain conditions. In general the TOPSIS method is based on the approach of ideal solution.

The fuzzy TOPSIS [4-13] method was developed by Chen in 2000 for problem with linguistic uncertainty.

Description of the method.

We consider the problem where decision DM makes decisions in linguistic form.

Consider all stages of fuzzy TOPSIS method:

1. First we define linguistic variables for criterion weight importance and the decisions with fuzzy trapezoidal numbers. 
Table 1. Linguistic variables for the importance of criterion weights

\begin{tabular}{|l|l|}
\hline \multicolumn{1}{|c|}{ Linguistic Variables } & \multicolumn{1}{c|}{ Trapezoidal Fuzzy Numbers } \\
\hline Very Low (VL) & $(0,0.1,0.2 .0 .3)$ \\
\hline Low (L) & $(0.1,0.3,0.45,0.7)$ \\
\hline Medium (ML) & $(0.4,0.5,0.7,0.8)$ \\
\hline High (H) & $(0.5,0.6,0.75,0.85)$ \\
\hline Very High (VH) & $(0.6,0.7,0.8,0.9)$ \\
\hline
\end{tabular}

Table 2. Linguistic variables for the decision

\begin{tabular}{|l|l|}
\hline \multicolumn{1}{|c|}{ Linguistic Variables } & \multicolumn{1}{c|}{ Trapezoidal Fuzzy Numbers } \\
\hline Very Poor (VP) & $(0,1,2,3)$ \\
\hline Poor (P) & $(1,3,4.7)$ \\
\hline Medium Poor (MP) & $(4,5,7,8)$ \\
\hline Good (G) & $(7,8,9.9 .25)$ \\
\hline Very Good (VG) & $(9,9.25,9.5,10)$ \\
\hline
\end{tabular}

2. Present the linguistic decisions as the matrix of outcomes (alternatives - criteria) $n$ - number of criteria, $m$ - number of alternatives

\begin{tabular}{|l|l|l|l|l|l|}
\hline & $\mathrm{C}_{1}$ & $\mathrm{C}_{2}$ & $\mathrm{C}_{3}$ & & $\mathrm{C}_{\mathrm{n}}$ \\
\hline $\mathrm{A}_{1}$ & $\tilde{X}_{11}$ & $\tilde{X}_{12}$ & $\tilde{X}_{13}$ & & $\tilde{X}_{1 n}$ \\
\hline $\mathrm{A}_{2}$ & $\tilde{X}_{21}$ & $\tilde{X}_{22}$ & $\tilde{X}_{23}$ & & $\tilde{X}_{2 n}$ \\
\hline $\mathrm{A}_{3}$ & $\tilde{X}_{31}$ & $\tilde{X}_{32}$ & $\tilde{X}_{33}$ & & $\tilde{X}_{3 n}$ \\
\hline & & & & & \\
\hline $\mathrm{A}_{\mathrm{m}}$ & $\tilde{X}_{m 1}$ & $\tilde{X}_{m 2}$ & $\tilde{X}_{m 3}$ & & $\tilde{X}_{m n}$ \\
\hline
\end{tabular}

Fig. 1. MCDM problem representation

Where $\tilde{X}_{i j}=\left(\tilde{a}_{i j}, \tilde{b}_{i j}, \tilde{c}_{i j}, \tilde{d}_{i j}\right)$ is fuzzy trapezoidal representation of linguistic terms.

3. Calculate normalized matrix $\tilde{R}=\left(r_{i j}\right), i=1,2, \ldots m ; j=1,2, \ldots n$

The normalized fuzzy decision matrix is calculated with the formulas given below, where $J$ and $J_{1}$ represent the maximization criteria set, and minimization criteria set respectively.

$$
\begin{gathered}
\tilde{r}_{i j}=\left(\frac{a_{i j}}{d_{j}^{*}}, \frac{b_{i j}}{d_{j}^{*}}, \frac{c_{i j}}{d_{j}^{*}}, \frac{d_{i j}}{d_{j}^{*}}\right), j \in J \\
\tilde{r}_{i j}=\left(\frac{a_{j}^{*}}{d_{i j}}, \frac{a_{j}^{*}}{c_{i j}}, \frac{a_{j}^{*}}{b_{i j}}, \frac{a_{j}^{*}}{a_{i j}}\right), \mathrm{j} \in J_{1} \\
d_{j}^{*}=\max _{i} d_{i j}, j \in J \\
a_{j}^{*}=\min _{i} a_{i j}, j \in J_{1}
\end{gathered}
$$

4. Calculate weighted decision matrix

$$
\tilde{V}=\left(v_{i j}\right), i=1,2, \ldots m ; j=1,2, \ldots n
$$

Where

$$
\tilde{v}_{i j}=\tilde{v}_{i j} \otimes \widetilde{w}_{j}, i=1,2, \ldots m ; j=1,2, \ldots n
$$

5. Determine positive and negative ideal solutions

$$
\begin{aligned}
& A^{+}=\left(\tilde{v}_{1}^{+}, \tilde{v}_{2}^{+}, \tilde{v}_{3}^{+}, \ldots \ldots . \tilde{v}_{n}^{+}\right) \\
& A^{-}=\left(\tilde{v}_{1}^{-}, \tilde{v}_{2}^{-}, \tilde{v}_{3}^{-}, \ldots \ldots . \tilde{v}_{n}^{-}\right)
\end{aligned}
$$

Where

$$
\begin{aligned}
& \tilde{v}_{1}^{+}=(1,1,1,1) \\
& \tilde{v}_{1}^{-}=(0,0,0,0)
\end{aligned}
$$


6. Calculate distances between actual decisions and positive and negative ideal solutions

$$
\begin{aligned}
& d_{i}^{+}=\sum_{j=1}^{n} d\left(\tilde{v}_{i j}^{+}, \tilde{v}_{j}^{+}\right) \mathrm{j}=1,2, \ldots \ldots \mathrm{m} \\
& d_{i}^{-}=\sum_{j=1}^{n} d\left(\tilde{v}_{i j}^{-}, \tilde{v}_{j}^{-}\right) \mathrm{j}=1,2, \ldots \ldots \mathrm{m}
\end{aligned}
$$

Where distance is calculated by formula

$$
D(\tilde{A}, \tilde{B})=\sqrt{\frac{1}{4}\left[\left(a_{1}-b_{1}\right)^{2}+\left(a_{2}-b_{2}\right)^{2}+\left(a_{3}-b_{3}\right)^{2}+\left(a_{4}-b_{4}\right)^{2}\right.}
$$

7. Calculate closeness coefficient for all alternatives

8. Determine acceptance level of decisions.

$$
C C_{i}=\frac{d_{i}^{-}}{d_{i}^{-}+d_{i}^{+}}, i=1,2, \ldots . m
$$

Table 3. Acceptance Criteria

\begin{tabular}{|l|l|}
\hline \multicolumn{1}{|c|}{ Closeness Coefficient $(\mathrm{CC}$ ) } & \multicolumn{1}{c|}{ Evaluation } \\
\hline$C C_{i} \in[0,0.2)$ & Not recommended \\
\hline$C C_{i} \in[0.2,0.4)$ & Recommended with high risk \\
\hline$C C_{i} \in[0.4,0.6)$ & Recommended with low risk \\
\hline$C C_{i} \in[0.6,0.8)$ & Acceptable \\
\hline$C C_{i} \in[0.8,1.0)$ & Accepted and preferred \\
\hline
\end{tabular}

9. Select decision with maximum of closeness coefficient.

Practical example. alternatives:

As practice problem we consider equipment selection problem with following 4 criteria and 3

C1- price

C2- noise level

C3- usability

C4- dimension

As seen for C3 optimal decision is maximum for other three criteria is minimum.

Consider application of fuzzy TOPSIS method for this problem. All computations were performed in Ms Excel.

1. Presentation of decisions in linguistic decision matrix

\begin{tabular}{|c|c|c|c|c|}
\hline & $C_{1}$ & $C_{2}$ & $C_{3}$ & $C_{4}$ \\
\hline$A_{1}$ & $\mathrm{VG}$ & $\mathrm{G}$ & $\mathrm{VG}$ & $\mathrm{MP}$ \\
\hline$A_{2}$ & $\mathrm{MP}$ & $\mathrm{G}$ & $\mathrm{G}$ & $\mathrm{VG}$ \\
\hline$A_{3}$ & $\mathrm{G}$ & $\mathrm{VG}$ & $\mathrm{MP}$ & $\mathrm{G}$ \\
\hline
\end{tabular}

The vector of criteria importance is presented as follows

$$
w=(M L, H, V H, H)
$$

2. Convert linguistic presentation in trapezoidal fuzzy numbers

\begin{tabular}{|c|c|c|c|c|}
\hline & $C_{1}$ & $C_{2}$ & $C_{3}$ & $C_{4}$ \\
\hline$A_{1}$ & $(9,9.25,9.5,10)$ & $(7,8,9.9 .25)$ & $(9,9.25,9.5,10)$ & $(4,5,7,8)$ \\
\hline$A_{2}$ & $(0.4,0.5,0.7,0.8)$ & $(7,8,9.9 .25)$ & $(4,5,7,8)$ & $(9,9.25,9.5,10)$ \\
\hline$A_{3}$ & $(7,8,9.9 .25)$ & $(9,9.25,9.5,10)$ & $(4,5,7,8)$ & $(7,8,9.9 .25)$ \\
\hline \multirow{2}{*}{$w=$} & $(0.4,0.5,0.7,0.8)$ & $(0.5,0.6,0.75,0.85)$ & $(0.6,0.7,0.8,0.9)$ & $(0.5,0.6,0.75,0.85)$ \\
\cline { 2 - 5 }
\end{tabular}


3. Calculate normalized fuzzy decision matrix by corresponding formulas

\begin{tabular}{|c|c|c|c|c|}
\hline & $C_{1}$ & $C_{2}$ & $C_{3}$ & $C_{4}$ \\
\hline$A_{1}$ & $(0.40,0.42,0.43,0.44)$ & $(0.76,0.78,0.88,1)$ & $(0.9,0.93,0.95,1)$ & $(0.5,0.57,0.8,1)$ \\
\hline$A_{2}$ & $(0.5,0.57,0.8,1)$ & $(0.76,0.78,0.88,1)$ & $(0.7,0.8,0.9,0.93)$ & $(0.4,0.42,0.43,0.44)$ \\
\hline$A_{3}$ & $(0.43,0.44,0.5,0.57)$ & $(0.7,0.74,0.76,0.78)$ & $(0.4,0.5,0.7,0.8)$ & $(0.43,0.44,0.5,0.57)$ \\
\hline
\end{tabular}

4. Calculate weighted normalized fuzzy decision matrix

\begin{tabular}{|c|c|c|c|c|}
\hline & $C_{1}$ & $C_{2}$ & $C_{3}$ & $C_{4}$ \\
\hline$A_{1}$ & $(0.16,0.21,0.3,0.36)$ & $(0.38,0.47,0.66,0.8)$ & $(0.54,0.65,0.76,0.9)$ & $(0.25,0.34,0.60 .0 .85)$ \\
\hline$A_{2}$ & $(0.2,0.29,0.56,0.8)$ & $(0.38,0.47,0.66,0.8)$ & $(0.42,0.56,0.72,0.83)$ & $(0.2,0.25,0.32,0.38)$ \\
\hline$A_{3}$ & $(0.17,0.22,0.35,0.46)$ & $(0.35,0.44,0.57,0.62)$ & $(0.24 .0 .35,0.56,0.72)$ & $(0.22,0.27,0.38,0.49)$ \\
\hline
\end{tabular}

5. Calculate distance between decisions and positive and negative ideal solutions

\begin{tabular}{|l|c|c|c|c|}
\hline & $C_{1}$ & $C_{2}$ & $C_{3}$ & $C_{4}$ \\
\hline$d\left(A_{1}, A^{+}\right)$ & 1.3 & 0.73 & 0.49 & 0.87 \\
\hline$d\left(A_{2}, A^{+}\right)$ & 0.95 & 0.73 & 0.62 & 1.25 \\
\hline$d\left(A_{3}, A^{+}\right)$ & 1.22 & 0.86 & 0.92 & 1.16 \\
\hline$d\left(A_{1}, A^{-}\right)$ & 0.52 & 1.15 & 1.37 & 1.1 \\
\hline$d\left(A_{2}, A^{-}\right)$ & 1.02 & 1.15 & 1.25 & 0.57 \\
\hline$d\left(A_{3}, A^{-}\right)$ & 0.62 & 0.97 & 0.98 & 0.68 \\
\hline
\end{tabular}

After calculating the distances between the alternatives and the fuzzy positive and fuzzy negative ideal solutions, we calculate the closeness coefficients for the all alternatives. The results is presented below

\begin{tabular}{|c|c|c|c|c|}
\hline & $d_{i}^{+}$ & $d_{i}^{-}$ & $C C_{i}$ & Ranking \\
\hline$A_{1}$ & 3.40 & 4.14 & 0.55 & 1 \\
\hline$A_{2}$ & 3.55 & 3.99 & 0.53 & 2 \\
\hline$A_{3}$ & 4.16 & 3.25 & 0.44 & 3 \\
\hline
\end{tabular}

According at the acceptance criteria of alternatives, all alternatives are determined as "Recommended with low risk". Since the closeness coefficients are ranked from the biggest to the smallest, as $\mathrm{CC}_{1}>\mathrm{CC}_{2}>\mathrm{CC}_{3}$, so alternative $\mathrm{A}_{1}$ is optimal.

Conclusions. The article is devoted to the problem of multi-criteria decision making for software selection. The analysis of existing methods for solving this problem is given. The fuzzy TOPSIS is used as a method for solving this problem. The issues of practical implementation of this method are discussed in details.

As practical problem the equipment selection problem with 4 criteria and 3 alternatives is considered. The results of the solution at all stages are presented. 


\section{REFERENCES}

1. Hwang, CL, Yoon, K. Multiple Attribute Decision Making: Methods and Applications. New York: Springer- Verlag, 1981.

2. V. Belton and T. Stewart, Multiple criteria decision analysis: an integrated approach. Springer Science \& Business Media, 2002.

3. A. Mardani, A. Jusoh, Khalil MD Nor, Z. Khalifah, N. Zakwan, A. Valipour. Multiple criteria decisionmaking techniques and their applications - a review of the literature from 2000 to 2014, ISSN: 1331-677X (Print), 2015.

4. Chen-Tung, C Extensions of the TOPSIS for Group Decision-Making Under Fuzzy Environment, Fuzzy Sets and Systems, 114(1),1-9, 2000.

5. Chen-Tung, C., Ching- Torng, L., Fn Huang, S. A Fuzzy Approach for Supplier Evaluation and Selection in Supply Chain Management. International Journal of Production Economics,102(2), 289-301, 2006.

6. Ashrafzadeh, M., Rafiei, F.M., Isfahani, N.M. and Zare, Z. Application of Fuzzy TOPSIS Method for the Selection of Warehouse Location: A Case Study, Interdisciplinary Journal of Contemporary Research in Business, 3(9):655-671, 2012.

7. Seyedmohammadi, J., Sarmadian, F., Jafarzadeh, AA, Ghorbani, MA, \& Shahbazi, F. Application of SAW, TOPSIS and fuzzy TOPSIS models in cultivation priority planning for maize, rapeseed and soybean crops. Geoderma, 310, 178-190, 2018.

8. Boran, FE, Genç, S., Kurt, M., \& Akay D. A multi-criteria intuitionistic fuzzy group decision making for supplier selection with TOPSIS method. Expert Systems with Applications, 36 (8), 11363-11368, 2009.

9. Matin, H.Z., Fathi, M.R, Zarchi, M.K ve Azizollahi. The Application of Fuzzy TOPSIS Approach to Personnel Selection for Padir Company, Iran, Journal of Management Research, 1-13, 2011.

10. Shih, H., Yuan, W. Lee, E. Group Decision Making for TOPSIS. IEEE, 3 (1),2712-2717, 2001.

11. Ta-Chung, Facility Location Selection Using Fuzzy TOPSIS Under Group Decisions. International Journal of Uncertainty, Fuzziness and Knowledge- Based Systems, 10 (6), 687-701. 2002.

12. Wang, T.C and Chang, T.H. Application of TOPSIS in Evaluating Initial Training Aircraft Under a Fuzzy Environment, Expert Systems with Applications, 33(4),870-880, 2007.

13. Seyedmohammadi, J., Sarmadian, F., Jafarzadeh, AA, Ghorban i, MA, \& Shahbazi, F. Application of SAW, TOPSIS and fuzzy TOPSIS models in cultivation priority planning for maize, rapeseed and soybean crops. Geoderma, 310, 178-190, 2018. 